\title{
Breast specimen shrinkage following formalin fixation
}

This article was published in the following Dove Press journal:

Pathology and Laboratory Medicine International

28 February 2014

Number of times this article has been viewed

\section{Christopher L Horn Christopher Naugler \\ Department of Pathology and Laboratory Medicine, University of Calgary, and Calgary Laboratory Services, Calgary, AB, Canada}

\begin{abstract}
Accurate measurement of primary breast tumors and subsequent surgical margin assessment is critical for pathology reporting and resulting patient therapy. Anecdotal observations from pathology laboratory staff indicate possible shrinkage of breast cancer specimens due to the formalin fixation process. As a result, we conducted a prospective study to investigate the possible shrinkage effects of formalin fixation on breast cancer specimens. The results revealed no significant changes in tumor size, but there were significant changes in the distance to all surgical resection margins from the unfixed to fixed state. This shrinkage effect could interfere with the accuracy of determining distance to margin assessment and tumor-free margin assessment. Thus, changes in these measurements due to the formalin fixation process have the potential to alter treatment options for the patient.
\end{abstract}

Keywords: breast margins, formalin, shrinkage, cancer

\section{Introduction}

Precise measurement of primary breast tumors, both in situ and invasive, and the subsequent margin assessment are crucial for accurate staging and subsequent patient therapy. ${ }^{1}$ Once the breast specimen is received in the pathology laboratory, pathologists, pathology residents, and pathologists' assistants are required to make an accurate gross assessment of the size of the tumor mass and the measurement of this mass to the surgical resection margins. The results of the measurements can assess the adequacy of initial surgery for patients ${ }^{2}$ and have added importance due to the increased usage of breast-conserving surgical methods and for subsequent patient management. ${ }^{2,3}$

The size of the tumor mass can have a direct impact on patient therapy. For example, in stage I tumors, if the reported size of the mass is less than $2 \mathrm{~cm}$ in greatest dimension, then radiation therapy may not be recommended, and if less than $1 \mathrm{~cm}$, adjuvant chemotherapy is not usually offered. ${ }^{4}$ Similarly, if the reported tumor size is greater than $5 \mathrm{~cm}$, neoadjuvant therapy is needed before surgery and radiation therapy to the chest wall may be considered after mastectomy. ${ }^{4}$

Additionally, the tumor distance to margins (DTM) is also critical in determining patient management. For surgical margins that are less than $2 \mathrm{~mm}$, re-excision is recommended (close margins at fascia is an exception)..$^{5}$ Additionally, radiotherapy boost is recommended in all patients 40 years of age or older regardless of margin, and in patients less than 40 years of age an individualized boost is based on risk assessment. ${ }^{5}$ In general, breast cancer patients with positive margins require additional surgery, patients with "close" margins are treated either with additional surgery or with external beam radiation therapy, and patients with negative margins are treated
Correspondence: Christopher Naugler 3535 Research Rd NW, Calgary,

AB, T2L 2K89, Canada

Tel +l 4037703756

Email christopher.naugler@cls.ab.ca submit your manuscript | www.dovepress.com

Dovepress

http://dx.doi.org// 0.2147/PLMI.S59842
Pathology and Laboratory Medicine International 2014:6 II-I4

(c) (7) (5) 2014 Horn and Naugler. This work is published by Dove Medical Press Limited, and licensed under Creative Commons Attribution - Non Commercial (unported, v3.0) BY LC License. The full terms of the License are available at http://creativecommons.org/licenses/by-nc/3.0/. Non-commercial uses of the work are permitted without any further permission for Deve Medical Press Limited, provided the work is properly attributed. Permissions beyond the scope of the License are administered by Dove Medical Press Limited. Information on how to request permission may be found at: http://www.dovepress.com/permissions.php 
with either radiation therapy or wide excision alone. ${ }^{1}$ Thus, if the DTM measurement taken by the pathology staff is inaccurate, then the resulting treatment for the patient may be suboptimal.

Anecdotal observations by the primary author and others in our laboratory suggested differences in size of breast tissue after overnight formalin fixation. A subsequent literature search revealed two studies which give conflicting conclusions as to the effect of formalin fixation on shrinkage of breast cancer specimens. ${ }^{2,6}$ Given the importance of changes to tumor size and distance of this tumor to nearest surgical margins, we examined the shrinkage effect of formalin fixation on breast cancer specimens in a series of specimens from our laboratory. We hypothesized that the process of formalin fixation has a shrinkage effect on both the tumor mass and the surrounding breast parenchyma tissue.

\section{Materials and methods}

Between August 2012 and August 2013, a prospective study was conducted which included 100 mastectomy and segmental mastectomy samples selected from the pathology service at the Foothills Medical Centre in Calgary, AB, Canada. Specimens were chosen so as to include resections that exhibited a grossly obvious solitary mass with distinguishable resection margins.

Specimens were received in the fresh (unfixed) state directly from the operating room at the Foothills Medical Centre. After being accessioned by the pathology laboratory staff, the specimens were weighed and then painted according to the standardized breast ink protocol for resection margins at Calgary Laboratory Services. After the ink was set dry, the breasts were serially sectioned, usually in a medial to lateral direction, with individual sections spaced approximately $1 \mathrm{~cm}$ apart from one another. Formalin-soaked paper towels were placed between each of the slices to allow for maximum formalin penetration and fixation while allowing the shape of the specimen to remain the same. The inking of the breast margins and the sectioning of the breast tissue are consistent with established methods of specimen preparation. ${ }^{7}$

Immediately after the breast tissue was sectioned, it was examined grossly for a well-defined tumor mass. Once a tumor mass was identified, the maximum size was recorded in one dimension in centimeters and up to one decimal place using a standard hand-held ruler. In addition, the DTM was recorded, also to one decimal place. As the initial cuts were made in a medial to lateral direction, the most common margins recorded were the superior, posterior, and inferior margins.
The specimens were then fully immersed into a $10 \%$ neutral buffered formalin-filled container for overnight fixation at a minimum 10:1 ratio as per current standard ${ }^{8}$ and at a minimum of 22 hours of fixation, which is longer than the current standard for a larger specimen. ${ }^{8}$ The next day, prior to gross dissection, the specimens were re-examined and the same measurements were recorded.

The measurements were made and recorded by a group of pathologists' assistants, who are the primary handlers of fresh surgical tissue at the Foothills Medical Centre. All of the pathologists' assistants involved in the study were instructed by the primary author in a standardized method to record the measurements to reduce interobserver variation. The same person who made the initial measurements may or may not have been the same person to take the second measurements. However, the pathologists' assistants were instructed to take the secondary (fixed) measurements on the same slice and in the same plane as the initial (fresh) measurements. In a majority of times (67\%), the same pathologists' assistant recorded both the initial measurement and secondary measurement to make sure the same slice and plane were measured consistently. In specimens where different pathologists' assistants recorded the initial and secondary measurements (33\%), consultation often occurred between the two to make sure consistent measurements were taken. In addition, the initial fresh specimen measurements were blinded to the individual doing the secondary formalin-fixed measurements to avoid bias.

\section{Statistical analysis}

A paired Student's $t$-test analysis was done on the DTM and tumor size measurements, and to correlate measurements from fixed DTM to microscopic DTM. Linear regression models were used to calculate the effect of patient age, formalin fixation time, size of the tumor, and the amount of shrinkage of breast tissue.

\section{Results}

A total of 100 segmental and total mastectomy specimens containing cancer were examined. The mean age of the patients was 62.33 (27-92) years. Fifteen tumors (15\%) were grade I, 31 tumors (31\%) were grade II, 49 tumors (49\%) were grade III, and three tumors (3\%) were of unknown grade. An extensive tumor-associated ductal carcinoma in situ was present in two cases (2\%) Eighty-five (85\%) tumors were classified as invasive ductal carcinomas, three (3\%) were classified as invasive lobular carcinoma, and 12 (12\%) were classified as mixed or other types of ductal carcinoma. 
The mean formalin fixation time for the specimens was 53.63 (22-106) hours. Length of fixation time varied due to either overnight fixation (at least 20 hours), weekend fixation ( $>48$ hours), or long weekend fixation ( $>72$ hours).

The mean maximum tumor dimension of the breast specimens in the unfixed state was $2.15(0.5-7.6) \mathrm{cm}$ while in the fixed state was $2.18(0.5-7.6) \mathrm{cm}$. This difference of $0.03 \mathrm{~cm}(1.6 \%)$ was not statistically significant. The mean size of the unfixed DTM compared with the fixed tissue is shown in Table 1. The differences in all three margins were statistically significant $(P<0.001$ for all), resulting in a $15 \%-22 \%$ loss of mean distance. Additionally, we correlated fixed gross measurements and microscopic measurements of DTM, with a random subsample analysis of 24 samples from our data and found a mean difference of $0.027 \mathrm{~cm}$, which was not statistically significant $(P=0.745)$.

Several additional factors were examined using multiple linear regression analysis. Age of the patient, formalin fixation time, and tumor size were all examined as independent variables compared with the dependent variable of differences to each margin. The only significant association was formalin fixation time on the distance to the superior $\operatorname{margin}(P=0.041)$.

\section{Discussion}

Changes in tumor size from the unfixed (natural) state to the fixed state could potentially alter patient treatment and outcomes. However, our results show that formalin fixation has no effect on tumor size. This is consistent with other studies which showed no significant shrinkage of tumor size after formalin fixation. , $3,6,9^{2,9}$

In contrast, our results did show that the surrounding breast parenchyma extending to the surgical resection margins shrank significantly. This has been a point of confusion in the literature as others have reported shrinkage in various types of tissue specimens. ${ }^{10-14}$ Specifically, there are documented instances of shrinkage due to formalin fixation observed in breast tissue ${ }^{2}$ and other fatty tissues. ${ }^{15}$ Indeed, Yeap et al observed a greater amount of shrinkage, reporting

Table I Mean paired differences (unfixed - fixed measurements) for margins of 100 breast specimens

\begin{tabular}{llll}
\hline $\begin{array}{l}\text { Resection } \\
\text { margin }\end{array}$ & $\begin{array}{l}\text { Mean paired } \\
\text { differences }(95 \% \mathbf{C I})\end{array}$ & $\begin{array}{l}\text { Percent } \\
\text { decrease }\end{array}$ & P-value \\
\hline Superior & $0.46(0.25-0.67)$ & 22 & $<0.001$ \\
Deep & $0.21(0.11-0.32)$ & 16 & $<0.001$ \\
Inferior & $0.34(0.19-0.49)$ & 15 & $<0.001$ \\
\hline
\end{tabular}

Note: All measurements are in centimeters.

Abbreviation: $\mathrm{Cl}$, confidence interval. a $34 \%$ decrease in mean closest free margin ${ }^{2}$ as compared with our $15 \%-22 \%$ difference. However, other authors have reported that formalin fixation does not contribute to cutaneous tissue shrinkage $e^{6,16,17}$ and may in fact lead to a slight increase in tissue ${ }^{17,18}$ and tumor ${ }^{6}$ size.

Previous literature suggests a chemical reaction to explain the shrinkage effects seen in breast and other cutaneous tissues. In essence, margin shrinkage is thought to stem from dehydration of fatty tissue due to formaldehyde degradation of lipids to their water-soluble derivatives. ${ }^{19}$ This fatty tissue shrinkage due to dehydration could explain the differences that we observed in the fatty parenchyma of the specimen and not in the dense tumor mass. However, authors of previous studies have suggested reasons for tissue shrinkage other than formalin fixation. Researchers have observed post-excision cutaneous shrinkage due to the intrinsic contractile properties of the tissue. ${ }^{16,17}$ Further, shrinkage of specimens is likely to occur immediately after surgical excision and prior to formalin fixation. ${ }^{1,20,21}$ These studies indicate that formalin fixation is not the main cause of specimen contractility, and thus not the main contributor to overall specimen shrinkage. ${ }^{17}$ Other researchers have also indicated differences in cutaneous shrinkage due to the aging process and solar elastosis, ${ }^{17}$ although our study does not indicate any differences related to the age of the patient. These findings are consistent with those of Yeap et $\mathrm{al}^{2}$ but in contrast with those of Krekel et al. ${ }^{6}$ However, Krekel et al used a different formalin concentration (4\%) and used water displacement for volume measurement which could account for rehydration and thus re-expansion of the breast tissue. ${ }^{6}$

In conclusion, we found that formalin fixation causes fatty tissue shrinkage in breast cancer specimens. This shrinkage effect could interfere with the accuracy of determining DTM measurements and tumor-free margin assessment. Additionally, since microscopic assessment is considered the "gold standard" for reporting tumor DTM, this shrinkage effect could influence which sections are taken grossly, in order to accurately assess these margins microscopically. In pathology reporting, DTM assessment has prognostic value and is crucial in determining patient management. ${ }^{16}$ Thus, changes in these measurements due to the formalin fixation process have the potential to alter treatment options for the patient. As an example, we found two of the specimens had a fresh measurement $>2 \mathrm{~mm}$ and a fixed measurement $<2 \mathrm{~mm}$ (only one confirmed microscopically) and thus had the potential to alter patient treatment options. We suggest that consideration should be given to reporting the margins in the unfixed state because this is most representative of the 
in vivo specimen. If pathologists prefer to report margins in the fixed state then they may want to consider the shrinkage changes in DTM due to formalin fixation.

\section{Author contributions}

CLH and CN conceived the study. CLH collected the data, contributed to the study design, and drafted the manuscript. $\mathrm{CN}$ performed the statistical analysis. Both authors contributed to revisions, and read and approved the final manuscript.

\section{Acknowledgments}

The authors would like to acknowledge the pathology laboratory staff at the Foothills Medical Centre in Calgary, AB, Canada for their contributions to this project. In particular, thanks to Bill Gorday, Dammika Bambaragama, Charity Greene, Christina Yang, and Chelsea Pearce.

\section{Disclosure}

The authors report no conflicts of interest in this work.

\section{References}

1. Graham RA, Homer MJ, Katz J, Rothschild J, Safaii H, Supran S. The pancake phenomenon contributes to the inaccuracy of margin assessment in patients with breast cancer. Am J Surg. 2002;184(2):89-93.

2. Yeap BH, Muniandy S, Lee SK, Sabaratnam S, Singh M. Specimen shrinkage and its influence on margin assessment in breast cancer. Asian J Surg. 2007;30(3):183-187.

3. Pritt B, Tessitore JJ, Weaver DL, Blaszyk H. The effect of tissue fixation and processing on breast cancer size. Hum Pathol. 2005;36(7): 756-760.

4. American Cancer Society. Treatment of invasive breast cancer, by stage, 2013. Available from: http://www.cancer.org/cancer/breastcancer/ detailedguide/breast-cancer-treating-by-stage. Accessed June 7, 2013.

5. Alberta Health Services. Adjuvant radiation therapy for invasive breast cancer, 2013. Available from: http://www.albertahealthservices.ca/hp/ if-hp-cancer-guide-br005-adjuvant-rt-invasive-breast.pdf. Accessed June 7, 2013.

6. Krekel NM, van Slooten HJ, Barbé E, de Lange de Klerk ES, Meijer S, van den Tol MP. Is breast specimen shrinkage really a problem in breastconserving surgery? J Clin Pathol. 2012;65(3):224-227.
7. Lester SC. Manual of Surgical Pathology. Philadelphia, PA, USA: Elsevier Saunders; 2010.

8. Hewitt M, Lewis PF, Cao PR. Tissue handling and specimen preparation in surgical pathology: issues concerning the recovery of nucleic acids from formalin-fixed, paraffin-embedded tissue. Arch Pathol Lab Med. 2008;132(12):1929-1935.

9. Chen CH, Hsu MY, Jiang RS, Wu SH, Chen FJ, Liu SA. Shrinkage of head and neck cancer specimens after formalin fixation. $J$ Chin Med Assoc. 2012;75(3):109-113.

10. Goldstein N, Soman A, Sacksner J. Disparate surgical margin lengths of colorectal resection specimens between in vivo and in vitro measurements. The effects of surgical resection and formalin fixation on organ shrinkage. Am J Clin Pathol. 1999;111(3):349-351.

11. Siu K, Cheung H, Wong J. Shrinkage of the esophagus after resection for carcinoma. Ann Surg. 1986;203(2):173-176.

12. Boonstra H, Oosterhuis J, Oosterhuis A, Fleuren G. Cervical tissue shrinkage by formaldehyde fixation, paraffin wax embedding, section cutting and mounting. Virchows Arch A Pathol Anat Histopathol. 1983;402(2):195-201.

13. Dobrin P. Effect of histologic preparation on the cross-sectional area of arterial rings. J Surg Res. 1996;61(2):413-415.

14. Hsu P, Huang H, Hseih C, et al. Effect of formalin fixation on tumor size determination in stage I non-small cell lung cancer. Ann Thorac Surg. 2007;84(6):1825-1829.

15. Docquier PL, Paul L, Cartiaux O, et al. Formalin fixation could interfere with the clinical assessment of the tumor-free margin in tumor surgery: magnetic resonance imaging-based study. Oncology. 2010;78(2):115-124.

16. Dauendorffer JN, Bastuji-Garin S, Guero S, Brousse N, Fraitag S. Shrinkage of skin excision specimens: formalin fixation is not the culprit. Br J Dermatol. 2009;160(4):810-814.

17. Kerns MJ, Darst MA, Olsen TG, Fenster M, Hall P, Grevey S. Shrinkage of cutaneous specimens: formalin or other factors involved? J Cutan Pathol. 2008;35(12):1093-1096.

18. Rolls G. Fixation and fixatives (1) - the process of fixation and the nature of fixatives. Leica Biosystems; 2012. Available from: http:// www.leicabiosystems.com/pathologyleaders/fixation-and-fixatives1-the-process-of-fixation-and-the-nature-of-fixatives/. Accessed January 16, 2014.

19. Jones D. The reactions of formaldehyde with unsaturated fatty acids during histological fixation. Histochem J. 1972;4(5):421-465.

20. Golomb F, Doyle J, Grin C, Kopf A, Silverman M, Levenstein M. Determination of preexcision surgical margins of melanomas from fixed-tissue specimens. Plast Reconstr Surg. 1991;88(5):804-809.

21. Hudson-Peacock M, Matthews J, Lawrence C. Relation between size of skin excision, wound and specimen. $J$ Am Acad Dermatol. 1995;32(6):1010-1015.
Pathology and Laboratory Medicine International

\section{Publish your work in this journal}

Pathology and Laboratory Medicine International is a peer-reviewed, open access journal focusing on innovative basic research and translational research related to pathology or human disease. The journal includes original research, updates, case reports, reviews and commentaries on current controversies. The Academic Sponsor

\section{Dovepress}

of this journal is the Chinese American Pathology Association (CAPA). The manuscript management system is completely online and includes a very quick and fair peer-review system. Visit http://www.dovepress.com/testimonials.php to read real quotes from published authors. 